\title{
O PRINCÍPIO DA CONCENTRAÇÃO DOS ATOS E A SEGURANÇA JURÍDICA DO ADQUIRENTE DE BOA-FÉ APÓS A LEI N. 13.097/2015
}

\author{
THE PRINCIPLE OF THE CONCENTRATION OF ACTS AND THE LEGAL SECURITY OF \\ THE GOOD FAITH PURCHASER AFTER LAW NO. 13.097 / 2015
}

\author{
Regiane Nistler* \\ Jéssica Cindy Kempfer*
}

\begin{abstract}
Resumo: A presente pesquisa abordou a concentração dos atos na matrícula do imóvel como instrumento de garantia ao adquirente de boa-fé, a qual inicia com um contexto histórico acerca da propriedade imobiliária no Brasil e a natureza jurídica dos serviços de registros públicos. Em seguida, esta estudou o conceito e a finalidade do Registro de Imóveis no Brasil, introduzindo o estudo da Concentração dos atos na matrícula, mas tendo como pano de fundo o Princípio da Segurança Jurídica. Por fim, foi abordado neste estudo como um grande avanço para a sociedade no que tange a Segurança Jurídica dos atos de registro.
\end{abstract}

Palavras-chave: Princípio; Concentração; Segurança Jurídica; Boa-fé; Propriedade Imobiliária.

\begin{abstract}
The present research addressed the concentration of acts in the registration of the property as a guarantee instrument to the buyer in good faith, which begins with a historical context about real estate in Brazil and the legal nature of public registry services. Then, it studied the concept and purpose of the Property Registry in Brazil, introducing the study of the
\end{abstract}

\footnotetext{
* Doutoranda e Mestre em Direito. Oficiala Interventora junto ao Ofício de Registro de Imóveis da Comarca de Campos Novos/SC nomeada pela Portaria n. 18/2018 da Corregedoria-Geral da Justiça de Santa Catarina. regianenistler@outlook.com.

** Mestra em Direito. Docente da disciplina de Direito Civil - Coisas da Universidade Luterana do Brasil (Ulbra), campus de Carazinho/RS. E-mail: jessicakempfer@gmail.com.
}

\section{Revista de Direito Urbanístico, Cidade e Alteridade | e-ISSN: 2525-989X | Encontro Virtual | v. 6 |} n. 2 | p. 18 - 55 | Jul/Dez. 2020. 
Concentration of acts in the registration, but having as a background the Principle of Legal Security. Finally, it was addressed in this study as a major advance for society with regard to the Legal Security of registration acts.

Keywords: Principle; Concentration; Legal Security; Good Faith; Real Estate.

\section{INTRODUÇÃO}

O problema acerca do qual a pesquisa em tela se ocupa está concentrado em averiguar se com o advento da Lei n. 13.097/2015, especialmente pelo texto do artigo 54, parágrafo único, que inicia a seção que trata dos registros na matrícula do imóvel, aumentou a Segurança Jurídica do adquirente de boa-fé.

Para tanto, foi estabelecida como hipótese a afirmação de que a Lei n. 13.097/2015 finalmente efetivou o Princípio da Concentração dos atos na matrícula do imóvel e naturalmente aumentou a Segurança Jurídica do adquirente de boa-fé.

O estudo teve como objetivo geral narrar o contexto histórico, jurídico e fático do Registro Imobiliário no Brasil, especialmente no que diz respeito aos seus efeitos perante a população, notadamente quanto a publicidade dos seus atos e especialmente a Segurança Jurídica que é esperada e necessária pela e para a sociedade.

No que diz respeito aos seus objetivos específicos a própria estrutura do texto os evidencia, à medida que é iniciado na seção primeira com a abordagem histórica, conceitual e jurídica do Registro de Imóveis, com o estudo das primeiras situações de posse do Brasil até a natureza jurídica dos atos registrais nos dias atuais.

Em seguida, a seção dois se debruçou a estudar o sistema e os efeitos do ato de registrar no Brasil, enfatizando a competência do Registro de Imóveis quanto a sua capacidade de reunir a partir dos atos de averbação e registro, conservar e dar publicidade dos assentos inerentes aos direitos reais da população. Por fim, esta segunda seção fez breve análise dos princípios registrais enquanto norteadores da atividade.

Em ato contínuo, o item três aborda finalmente o Princípio da Concentração dos atos na matrícula, destacando que o cadastro imobiliário (matrícula) deve possuir todos os direitos 
reais e atos inerentes ao imóvel acerca do qual faz menção a inscrição.

Por derradeiro, o trabalho aborda as mudanças trazidas ao cenário jurídico com o advento da Lei n. 13.097/2015, que a partir do parágrafo único do artigo 54, consagrou o Princípio da Concentração dos atos da matrícula como um grande caminho para a plena Segurança Jurídica nos negócios imobiliários no Brasil.

O método adotado na confecção da pesquisa foi o dedutivo, especialmente com consultas à bibliografias como doutrinas, jurisprudências e legislação.

\section{CENÁRIO HISTÓRICO, CONCEITUAL E JURÍDICO DA PROPRIEDADE IMOBILIÁRIA NO BRASIL}


São imensuráveis as relações de ordem jurídica estabelecidas a todo o tempo pela sociedade, "cabendo aos Poderes Constituídos buscar meios de garantir a segurança jurídica nas transações nela praticadas, principalmente nas imobiliárias.” (REMÉDIO; AGUIAR, 2017)

Contudo, antes de efetuar abordagem quanto as características hodiernas da atividade registral, imperioso traçar, ainda que brevemente o seu arcabouço histórico, demonstrando que a relevância da atividade registral tem suas raízes no descobrimento do Brasil.

\subsection{Apontamentos históricos acerca da propriedade no Brasil}

Inicialmente, na descoberta do Brasil, o Rei de Portugal adquiriu o título de origem da posse, repartindo o território em capitanias hereditárias que eram governadas por donatários, que praticavam a cessão de seus direitos decorrentes da posse aos que habitavam as capitanias por meio das intituladas cartas de sesmaria, sendo que estas eram entregues primeiro pelos donatários das capitanias, em seguida pelo governo geral, e, por fim, pela Coroa de Portugal. (AGUIAR VALLIM, 1984, p. 66)

Contudo, como se sabe, o sistema implementado pelas cartas de sesmarias proporcionava privilégios apenas para os nobres e indivíduos que integravam a alta Corte e, dessa forma, considerando a extensão territorial do Brasil, a propriedade era sub aproveitada, e tampouco se observava a função social da propriedade. (REMÉDIO; AGUIAR, 2017)

Adiante, em 1843 nasceu a Lei Orçamentária n. 317, através da qual fora criado o registro de hipotecas, que tinha como objetivo tornar a terra o núcleo da concessão de crédito.

Assim, o sistema de registro de hipotecas teve previsão, ainda que de maneira tímida na Lei Orçamentária n. 317, de 21.10.1843 (art. 35), que foi regulamentada pelo Decreto n. 482, de 14.11.1846. Em 1864, foi editada a Lei n. 1237 que, com o Regulamento n. 3.453, de 1865, criou o registro geral para transcrever os títulos de transmissão de imóveis sujeitos à hipoteca e a inscrição destas, sendo que este sistema foi confirmado pelos diplomas legais que o sucederam: Decreto do Império ou Lei n. 3.272, de 05.10.1885; Decreto n. 169-A, de 19.01.1890; e Decretos n. 370 e n. 544, ambos de 1890.

Todavia, este sistema se mostrava parcial e fragmentário, pois permitia apenas a 
transcrição de atos entre vivos que representavam constituição ou transmissão de direitos reais acerca de bens suscetíveis de hipoteca, assim como a inscrição de garantias reais. (LOUREIRO, 2019, p. 548) 
Este cenário foi alterado com o advento do Código Civil de 1916, no qual a partir do artigo 856 demonstra que o Registro Geral foi substituído pelo Registro de Imóveis, no qual fora mantida a transcrição, mas com uma alteração importante, sendo-lhe dada nova roupagem, resultando em prova de propriedade juris tantum, logo, admitindo em contrário. (MELO, 2004)

Em seguida, com a Lei n. 4.827 de 1924 que foi regulamentada através do Decreto n. 18.542 de 1928, e no Decreto n. 4.857, de 1939, foi inserido no sistema de registro o Princípio da Continuidade, ou seja, para qualquer transcrição ou inscrição era exigência o registro do ato anterior.

A título de adendo necessário consignar que o Princípio da Continuidade ou Trato Sucessivo está consagrado no artigo 195 da Lei n. 6.015/73 e significa que nenhum título pode ingressar no Registro de Imóveis sem que o título que lhe antecedeu esteja registrado. Logo, é necessário que haja ligação, encadeamento entre os atos, de modo que não se verifique lacunas ou interrupções no cenário registral. Ou seja, "a sequência entre um registro e outro não pode ser quebrada, vale dizer, para que uma pessoa possa transmitir a propriedade, o título de aquisição desta propriedade deve estar registrado. " (DEBS, 2018, p. 608)

No ano de 1973 nasce a Lei n. 6.015, que reúne em um único diploma legal todos os princípios que norteiam a atuação do Registro de Imóveis, à medida que aperfeiçoa uns e cria outros, mas revolucionando o cadastro predial do Brasil, especialmente no que diz respeito aos livros, uma vez que além de diminuir a quantidade, centralizou um livro principal no imóvel, criando a figura da matrícula (MELO, 2004).

Assim, como leciona Lamana Paiva (2013) "o Direito registral somente criou sua autonomia com a Lei 6.015/73. Até então era mero apêndice do Código Civil. Nem a cadeira estática de Direito notarial e registral tínhamos."

Por fim, o Código Civil de 2002 apresentou mais atenção em relação aos registros públicos, à medida que consagrou os princípios do direito registral, confirmando a relevância do Registro de Imóveis, através dos artigos 1.227, 1.245 a 1.247, por exemplo, que serão tratados adiante em seção específica.

\subsection{Natureza jurídica dos serviços de registro}


Antes de tratar acerca da competência específica do Registro de Imóveis no Brasil importante tratar da matéria no que tange a delimitação de sua natureza jurídica. Dessa forma, prevê o artigo 236 da Constituição Federal que "os serviços notariais e de registro são exercidos em caráter privado, por delegação do Poder Público.” (BRASIL, 1988) 
Dos dispositivos colacionados Serra e Hipólito Serra (2016, p. 13) traçam o seguinte conceito:

[...] os serviços notariais e de registros são recebidos pelo particular por meio de delegação. Delegar consiste em atribuir atividade própria da administração a um ente privado ou público. Assim, conclui-se, pela análise dos referidos textos, que as atividades notariais e registrais são públicas por excelência, sendo exercidas, contudo, em caráter privado, por particulares investidos na função pública pordelegação. Dito de outra forma, hoje predomina o entendimento de que a natureza da atividade é de serviço público, mas sua gestão é particular.

Ainda quanto ao caráter privado do exercício da atividade, verifica-se que os prepostos, funcionários recrutados para auxílio na prestação dos serviços, devem ser contratados de forma direta pelo delegado, por meio do regime de previdência comum (INSS) e pelas regras contidas na Consolidação das Leis do Trabalho (CLT). Existem, nos dias atuais, em algumas serventias, os chamados funcionários estatutários, que se tratam dos colaboradores regidos por normas específicas, em diversos casos semelhantes às dos funcionários públicos estaduais. (SERRA; HIPÓLITO SERRA; 2016, p. 13-14)

Contudo, esta modalidade de prepostos é herança do sistema que vigorava antes da Constituição Federal de 1988, no qual não estava claro o caráter privado do exercício da atividade, sendo que estas eram praticadas juntamente com os serviços judiciais. Todavia, estes colaboradores, por não serem titulares de cargo público, nem terem, em regra, passado pelo concurso público, não são funcionários públicos, mas sim, prepostos com regime previdenciário que tem formato diferenciado. (SERRA; HIPÓLITO SERRA; 2016, p. 14)

Quanto a remuneração dos registradores importa consignar que ela é feita por meio dos emolumentos que são pagos pelos usuários, em relação aos atos por aqueles praticados. A regulamentação dos emolumentos é de competência de cada Estado, conforme as normas gerais

que são fixadas pela Lei Federal n. 10.169, de 29 de dezembro de 2000. (SERRA; HIPÓLITO SERRA; 2016, p. 14)

No que diz respeito a natureza das custas dos serviços extrajudiciais importa consignar que ela ainda é discutida pela doutrina, mas há bastante tempo tem o Supremo Tribunal Federal definido o entendimento de que se trata de taxa, que é uma modalidade de tributo, conforme se extrai do RE n. 116.208-2, com publicação no Diário Oficial da União - DOU em 08.06.1990. 
(SERRA; HIPÓLITO SERRA; 2016, p. 14)

Ademais, a delegação do serviço pelo Poder Público acontece através de concurso público de provas e títulos, efetuado pelo Poder Judiciário, com atuação, em todas as fases, da Ordem dos Advogados do Brasil (OAB), do Ministério Público (MP), de um notário e de um 
registrador, como prevê o artigo 15 da Lei n. 8.935/94, de modo que nenhuma delegação pode permanecer vaga, sem a abertura de concurso público, por período superior a seis meses, um objetivo que tem sido seriamente buscado pelo Conselho Nacional de Justiça (CNJ), por meio de suas normas, regulamentando concursos desta área, como se extrai das Resoluções n. 80 e n. 81 de 09 de junho de 2009. (SERRA; HIPÓLITO SERRA; 2016, p. 14)

Além disso, destaca Loureiro (2019, p. 546):

O registrador é um profissional do direito, dotado de fé pública, a quem é delegado o exercício da atividade de registro. $\mathrm{O}$ registrador tem o dever de prestar os serviços a seu cargo de modo adequado, observando rigorosamente os deveres próprios da delegação pública em que estão investidos, a fim de garantir a autenticidade, publicidade, segurança, disponibilidade e eficácia dos atos jurídicos constitutivos, translativos ou extintivos de direitos reais sobre imóveis e atividades correlatas (arts. 1, 12 e 30, II, da LNR).

Inclusive, a atuação do registrador imobiliário vem prevista no artigo 12 da Lei n. 8.935/1994 (BRASIL, 1994):

Art. 12. Aos oficiais de registro de imóveis, de títulos e documentos e civis das pessoas jurídicas, civis das pessoas naturais e de interdições e tutelas compete a prática dos atos relacionados na legislação pertinente aos registros públicos, de que são incumbidos, independentemente de prévia distribuição, mas sujeitos os oficiais de registro de imóveis e civis das pessoas naturais às normas que definirem as circunscrições geográficas.

Destarte, o direito registral imobiliário pode ser definido como a parte específica do direito de registros públicos que se preocupa com o conjunto de princípios e normas que têm como objetivo regular a função do oficial de Registro de Imóveis e a organização e o funcionamento das instituições do Estado que têm o dever de receber os atos e documentos referentes aos direitos reais acerca de bens imóveis ou aqueles que os afetam, assim como as formas e resultados dos respectivos registros e os efeitos deles decorrentes. (LOUREIRO, 2019, p. 547)

É possível concluir pelas lições de Loureiro (2019, p. 547) em relação ao Direito Registral Imobiliário que ele

[...] tem por objeto a publicidade da propriedade de bens imóveis e de outros direitos

Revista de Direito Urbanístico, Cidade e Alteridade | e-ISSN: 2525-989X | Encontro Virtual | v. 6 | n. 2 | p. 18 - $55 \mid$ Jul/Dez. 2020. 
reais imobiliários, visando à proteção dos titulares de tais direitos reais (publicidade estática) e também a garantia do tráfico jurídico dos bens imóveis (publicidade dinâmica). Destarte, a razão de ser do Direito registral é diminuir o risco dos adquirentes de imóveis ou direitos a eles relativos, por meio de uma maior segurança jurídica no tráfico imobiliário e, consequentemente, diminuindo os custos da transação e contribuindo para a diminuição de litígios envolvendo imóveis. 
A publicidade mencionada pelo autor, aqui tratada como o Princípio da publicidade e já iniciando a abordagem acerca dos efeitos da atividade registral a ser trabalhada no tópico seguinte, vale dizer que tem a finalidade de outorgar segurança às mais variadas relações jurídicas, já que assegura a qualquer interessado o conhecimento do teor do acervo das serventias notariais e registrais e garante sua oponibilidade em relação a terceiros, sendo este o seu marco distintivo. No Brasil isso acontece por meio de certidão, a intitulada publicidade formal ou indireta. (DEBS, 2018, p. 599)

Em relação ao Registro de Imóveis de forma objetiva explicam Serra e Hipólito Serra (2016, p. 164) "pelo princípio da publicidade todos os atos inscritos no registro de imóveis tornam-se públicos e somente sua inscrição faz com que estes atinjam a publicidade almejada perante terceiros."

\section{O ATO DE REGISTRAR: SISTEMA E EFEITOS DO REGISTRO DE IMÓVEIS.}

O Registro de Imóveis, como iniciada a demonstração na seção anterior e será abordado com mais especificidade neste tópico, ostenta a importância de uma instituição de natureza jurídica organizada e fiscalizada pelo ente estatal e que faz proclamas oficiais no que diz respeito a questões de ordem jurídica em relação a propriedade e suas modificações.

O que se pretende introduzir em alguns aspectos e ratificar em outros nesta seção é a relevância e os impactos decorrentes da atividade do Registro de Imóveis em toda a sociedade, especialmente nos negócios jurídicos.

\subsection{Conceito e finalidade do Registro de Imóveis no Brasil}

A atuação do Registro de Imóveis no Brasil, assim como os demais serviços notariais e de registro, tem como objetivo garantir a publicidade, a autenticidade, a segurança e a eficácia dos atos e negócios jurídicos celebrados diariamente pela sociedade. (LOUREIRO, 2019, p. 546).

A competência do Registro de Imóveis na legislação está prevista de forma sucinta no artigo 172 da Lei n. 6.015/73 (BRASIL, 1973) também chamada de Lei dos Registros Públicos, 
prevendo o seguinte:

Art. 172 - No Registro de Imóveis serão feitos, nos termos desta Lei, o registro e a averbação dos títulos ou atos constitutivos, declaratórios, translativos e extintos de direitos reais sobre imóveis reconhecidos em lei, "intervivos" ou " mortis causa" quer 
para sua constituição, transferência e extinção, quer para sua validade em relação a terceiros, quer para a sua disponibilidade.

Assim, de maneira geral é possível afirmar que o Registro de Imóveis é a instituição que tem competência para a formação e conservação do assento dos dados relacionados aos direitos reais que tem previsão na legislação pátria, assim como das demais informações cuja inscrição a lei determinar para fins de publicidade. (SERRA; HIPÓLITO SERRA; 2016, p. 16)

Acerca do princípio da inscrição, consagrado no artigo 172, entende-se que a transferência do direito de natureza real por ato inter vivos apenas acontece mediante o registro do título translativo no Registro de Imóveis. Dessa forma, "a constituição, transmissão, modificação ou extinção dos direitos reais sobre imóveis só se operam entre vivos, mediante sua inscrição no registro. " (DEBS, 2018, p. 1.061)

Ainda, nas lições de Afrânio de Carvalho (1976) o princípio da inscrição tem dois enfoques: o primeiro, constitutivo, à medida que está relacionado com o nascimento do fólio real; e o segundo, declarativo, que tem como objetivo efetuar a publicação dos atos jurídicos para que produzam seus efeitos, tutelando o patrimônio alcançado pelo ato de registrar.

Portanto, o Registro de Imóveis consiste na realização do cadastro da propriedade imobiliária, que demonstre sua situação atual e por meio dele são realizadas todas as mudanças, alterações e extinções dos direitos referentes ao imóvel. Trata-se do arcabouço concentrado de todas as informações referentes a propriedade imobiliária, caracterizado pela publicidade, autenticidade, segurança e eficácia de cunho jurídico. (DEBS, 2018, p. 1.061)

Desta forma, é possível ampliar a competência do Registro de Imóveis para incluir a organização, a conservação e o controle do ingresso de atos no fólio real. Este controle é efetuado por meio da análise da legalidade dos títulos e da conformação do ato que se objetiva inscrever aos requisitos e exigências de ordem normativa, o que se intitula qualificação registral. (SERRA; HIPÓLITO SERRA; 2016, p. 17)

Ademais, importante observar que o termo "fólio real" possui diversos significados. Pode tanto fazer menção a uma classificação dos sistemas registrais imobiliários existentes no globo ou fazer referência a todos os dados arquivados na serventia, ou apenas ser utilizado para designar a matrícula (Livro n. 2). (SERRA; HIPÓLITO SERRA; 2016, p. 17) 
Ainda, o artigo 1.227 do Código Civil de 2002 apresenta um dos pilares jurídicos do Registro de Imóveis que possui a seguinte redação: 
Art. 1.227. Os direitos reais sobre imóveis constituídos, ou transmitidos por atos entre vivos, só se adquirem com o registro no Cartório de Registro de Imóveis dos referidos títulos (arts. 1.245 a 1.247), salvo os casos expressos neste Código.

Verifica-se que o colacionado artigo faz distinção entre o modo de aquisição dos bens imóveis em relação aos bens móveis, o que se dá pela simples tradição, ou seja, entrega do bem, mas n o caso de bens imóveis a aquisição só acontece após o registro. (DEBS, 2018, p. 1.061)

Além disso, o Código Civil arrola no artigo 1.225 os direitos reais, sendo eles:

Art. 1.225. São direitos reais:I - a propriedade;II - a superfície;III - as servidões;IV o usufruto;V - o uso;VI - a habitação;VII - o direito do promitente comprador do imóvel;VIII - o penhor;IX - a hipoteca;X - a anticrese.XI - a concessão de uso especial para fins de moradia; (Incluído pela Lei no 11.481, de 2007); XII - a concessão de direito real de uso; e (Redação dada pela Lei $n^{\circ} 13.465$, de 2017); XIII - a laje. (Incluído pela Lei ${ }^{\circ} 13.465$, de 2017)

No entanto, necessário destacar que esse rol não é taxativo, ou seja, não exaure a existência de outros direitos, desde que positivados, como por exemplo, a alienação fiduciária. (DEBS, 2018, p. 1.061)

\subsection{Breves apontamentos acerca dos Princípios que norteiam a atividade registral}

Inicialmente e de forma breve convém destacar o que é Princípio e utilizando as lições de Miguel Reale (2002, p. 305), para quem os Princípios são "verdades fundantes" de um arcabouço de conhecimento, assim evidenciadas, tanto por serem realmente claras ou por serem comprovadas, mas também por motivações de natureza prática e de características operacionais, ou seja, como requisitos necessários pelas necessidades do ato de pesquisar e da práxis.

São tão relevantes, explica Loureiro (2019, p. 582), que "na hierarquia das regras jurídicas, o princípio prevalece sobre a norma, de modo que exerce um papel preponderante não apenas para a interpretação, como também para a integração do ordenamento jurídico. ”

A princípio, são três as funções dos princípios registrais: a) função informadora ou integradora, uma vez que são usados como modo de orientação ou direção fundamental para os ditames concretos possuam por conteúdo disposições lógicas; b) função científica, à medida que permitem construir de forma racional o marco regulatório dos registros públicos como um 
todo e c) função aplicativa, pois representam facilitadores quanto a interpretação das normas jurídicas, proporcionando direções de cunho científico para solucionar conflitos envolvendo o direito registral. (LOUREIRO, p. 583-584) 
Por uma questão de limitação física não poderão ser abordados neste trabalho todos os princípios do Direito Registral, contudo, o princípio que não pode ser negligenciado sem dúvida é a da Segurança Jurídica.

Isso porque a própria Constituição Federal consagra este princípio no artigo $5^{\circ}$,inciso XXXVI, atribuindo a ele o caráter de direito fundamental e garantia aos indivíduos em todo o território nacional.

Inclusive, para Melo (2004) se efetuarmos um estudo cauteloso em relação aos princípios do direito registral, concluiremos que "todos, sem exceção, colimam trazer ao álbum imobiliário a segurança necessária que o Direito espera e necessita para a estabilidade das relações jurídicas."

É possível dividir o princípio da Segurança Jurídica dentro das Serventias Imobiliárias em duas modalidades. A primeira delas verificamos com a chamada segurança jurídica dinâmica, que fica evidenciada quando o adquirente de um imóvel apresenta seu título junto ao Registro de Imóveis e por conseguinte tem garantido todos os benefícios decorrentes do direito registrado. (SERRA; HIPÓLITO SERRA; 2016, p. 140)

Já a segunda modalidade é denominada Segurança Jurídica estática e trata da garantia assegurada pela estabilidade dos direitos reais que decorre da regulamentação e observância do arcabouço jurídico no que diz respeito a esses direitos. (SERRA; HIPÓLITO SERRA; 2016, p. 140)

Outro princípio a ser lembrado é o da Legalidade que de acordo com Loureiro (2019, p. 594)

[...] não basta a inscrição para que o título tenha acesso ao Registro de Imóveis. É preciso que o título seja válido e perfeito, de forma que antes que se proceda ao registro, o documento deve passar por um exame de qualificação por parte do registrador. Em outras palavras, a validade do registro depende da validade do negócio jurídico que lhe dá suporte.

Ou seja, "para que o título seja válido e perfeito e dê ensejo ao registro, não basta a inscrição. É necessário que o documento passe por um exame de qualificação por parte do registrador." (DEBS, 2018, p. 602) Vale lembrar que os títulos judiciais também devem passar pela qualificação registral. 


\section{O ADVENTO DA LEI N. 13.097/2015 E A CONSAGRAÇÃO DO PRINCÍPIO DA CONCENTRAÇÃO.}


O princípio da Concentração encontra-se implícito da Lei n. 6.015/73 em razão da instituição da matrícula. O conceito de matrícula foi concebido como sendo o cadastro imobiliário que deve conter todos os direitos reais e atos inerentes ao imóvel em questão. Dessa forma, através do conceito de matrícula é possível perceber o conceito do Princípio da Concentração, que será nessa seção brevemente estudado. (SERRA; HIPÓLITO SERRA, 2016, p. 166).

Ou seja,

Segundo o Princípio da Concentração, todos os direitos reais incidentes sobre determinado imóvel devem estar reunidos na matrícula dele, não existindo possibilidade de outros direitos virem a afetá-los caso nela não se encontrem inscritos. (SERRA; HIPÓLITO SERRA, 2016, p. 166).

É possível dizer que o Princípio da Concentração tem em sua natureza o objetivo de concentrar todas as informações e direitos importantes na matrícula de um imóvel, logo, qualquer fato que ali não esteja registrado ou averbado não poderá ser oposto a terceiro. (REMÉDIO; AGUIAR, 2017)

\title{
3.1 O Princípio da Concentração
}

Na doutrina de Lamana Paiva e Erpen (2014, IRIB),

\begin{abstract}
Com a adoção da matrícula, para onde devem ser levados todos os atos oponíveis a terceiros, consagrou-se, como única prática saudável, o princípio da concentração. O que não está na matrícula não existe para o mundo jurídico, salvo a usucapião e a servidão de trânsito aparente, porque aí a publicidade é natural. Os defensores desse princípio têm apregoado que, em se adotando o sistema tabular, deve ele ser completo. A matrícula (fólio real), em substituição às antigas transcrições de cunho pessoal e cronológico, deve ser tão completa que dispense diligências outras, em sintonia com a segurança jurídica que o Constituinte consagrou. Deve ser satisfativo.
\end{abstract}

A grosso modo, portanto, caso não seja efetuada a averbação da penhora, não poderá a venda da propriedade do executado em favor do terceiro de boa-fé ser intitulada como ineficaz perante o credor exequente. Da mesma forma ocorre com a inscrição de usufruto, hipoteca, entre outros institutos jurídicos, que na hipótese de não constarem do assento, o adquirente 
recebe o imóvel desembaraçado desses ônus. (LOUREIRO, 2019, p. 639)

Em relação ao fundamento legal específico do Princípio da Concentração, antes de tratar do advento da Lei n. 13.097/2015, podemos citar o art. 167, inciso II, item 5, cumulado com o artigo 246, ambos da Lei n. 6.015/1973: 
Art. 167 - No Registro de Imóveis, além da matrícula, serão feitos.

(...)

II - a averbação:

(...)

5) da alteração do nome por casamento ou por desquite, ou, ainda, de outras circunstâncias que, de qualquer modo, tenham influência no registro ou nas pessoas nele interessadas;

Art. 246 - Além dos casos expressamente indicados no item II do artigo 167, serão averbados na matrícula as subrogações e outras ocorrências que, por qualquer modo, alterem o registro. (BRASIL, 1973)

Além disso, interessante citar a $2^{\mathrm{a}}$ Jornada Ibero-Americana de Derecho Registral, que aconteceu em Cuba no período de 16 a 19 de maio do ano de 2001, no qual a Delegação Brasileira deu bastante atenção ao Princípio da Concentração, que, inclusive, constou do relatório do evento nos seguintes termos:

Estudiar la propuesta del Delegado Brasileño con relación al principio de la Concentración de los Actos Administrativos y Judiciales de manera que estén contenidos en el Folio Real a fin de poseer una verdadera historia de la finca. (JACOMINO, 2017, p.75)

Outrossim, o Princípio da Concentração é um objetivo que vem sendo perseguido pela doutrina e jurisprudência, à medida que recebe cada vez mais adeptos nos julgados, como será destacado a seguir, e segue refletido em disposições legais que o assegurem, como por exemplo em casos de registro de penhora e compromissos de compra e venda. (SERRA; HIPÓLITO SERRA, 2016, p. 166).

No que tange ao registro de penhora verificamos que, apesar de o artigo 169 da Lein. 6.015/73, que prevê que todos os atos enumerados no artigo 167 são obrigatórios e serão feitos no cartório da situação do imóvel, adicionado ao fato de que a penhora é um dos atos que tem previsão no respectivo artigo, se efetuarmos análise de julgados mais antigos do Superior Tribunal de Justiça, encontraremos diversas decisões que narram a ausência de necessidade do registro da penhora frente a sua publicidade processual. (SERRA; HIPÓLITO SERRA, 2016, p. 166-167).

Diante disso, verificamos ainda a Lei n. 8.953, de 13.12.1994, que foi a primeira lei que definiu a necessidade de registro da penhora como requisito para a validade ou eficácia contra terceiros, sendo esta linha mantida por todas as legislações que vieram em seguida e que 
alteraram o tema no Código de Processo Civil. (SERRA; HIPÓLITO SERRA, 2016, p. 167).

Estas alterações legislativas motivaram a edição da Súmula 375 do Superior Tribunal de Justiça, de 13.08.2009, que ratificou a imprescindibilidade do registro da penhora, para que esta atinja os requisitos da publicidade imobiliária, ao afirmar que: "O reconhecimento da 
fraude à execução depende do registro da penhora do bem alienado ou da prova da má-fé do terceiro adquirente". (SERRA; HIPÓLITO SERRA, 2016, p. 167).

Dessa forma, é possível perceber, especialmente pelo texto do artigo 1.418, que apenas o titular de direito real, ou seja, o titular de compromisso de compra e venda acerca do qual não foi firmado arrependimento e que foi registrado no registro de imóveis, frise-se, tem direito a recorrer à utilização da adjudicação compulsória do imóvel, na hipótese do promitente vendedor não faça a outorga da escritura em formato definitivo após cumpridas as condições do contrato. (SERRA; HIPÓLITO SERRA, 2016, p. 168).

No entanto, apesar de todos os estudos acerca da matéria e até mesmo a conquista da abordagem madura acerca do assunto em cenário jurisprudencial, o princípio da concentração em nosso país teve sua inserção formal apenas com o Projeto de Lei n. 5.708 do ano de 2013, mas o mesmo não avançou para votação e a esperada aprovação.

Ademais, o poder executivo federal editou recentemente a Medida Provisória n. 656, de 07.10.2014, que foi convertida na Lei n. 13.097/2015, que com seu advento representou enorme progresso em relação ao Princípio da Concentração, conforme será tratado na seção a seguir.

\subsection{O Princípio da Concentração após a Lei n. 13.097/2015.}

No que tange a previsão legal do Princípio da Concentração, ou seja, sua introdução formal no arcabouço jurídico, destacam Lamana Paiva e Erpen (2014, IRIB):

Mostrava-se necessária a explicitação desse princípio, através de um texto legal incisivo, conferindo-lhe a amplitude e o reconhecimento que ele necessitava, passando a promover uma verdadeira revolução no âmbito do Direito Registral Imobiliário brasileiro.

A exposição de motivos do projeto da Medida Provisória n. 656, de 2014 (BRASIL, 2014) é clara e objetiva quanto a previsão do Princípio da Concentração ao descrever em seu item 58 que: "O Projeto de Medida Provisória visa também adotar o princípio da concentração de dados nas matrículas dos imóveis, mantidas nos Serviços de Registro de Imóveis. ” 
Adiante, o item 59 da exposição de motivos do projeto (BRASIL, 2014) narra a preocupação quanto a assimetria de informação. Por um lado, o vendedor ostenta informações seguras acerca da sua própria conjuntura econômica e jurídica e sobre a circunstância física e jurídica do imóvel objeto do negócio. Por outro lado, o comprador e financiador não ostentam, 
de plano, essas informações, à medida que necessitam buscá-las em outras fontes, consideradas até mesmo fidedignas.

A inserção da averbação premonitória na matrícula imobiliária proporciona publicidade a execução de modo que acontece a presunção no que tange a fraude à execução a alienação ou oneração de bens feita depois da averbação, garantindo-se que estas sejam ineficazes em relação a ação de execução ali gravada. (SERRA; HIPÓLITO SERRA, 2018, p. $155)$.

No que tange ao cuidado evidenciado no artigo 792 do CPC é possível concluir que para ficar evidenciada a fraude à execução, os credores devem averbar suas respectivas ações ou qualquer outro tipo de constrição na matrícula do imóvel, de modo que havendo o bem sido alienado ou onerado a terceiro, este não poderá se utilizar da alegação de boa-fé, uma vez que os atos ali estavam inscritos.

Em contrapartida, se não houver a efetivação da averbação no registro, o caminho do exequente se torna mais difícil, pois caberá a ele demonstrar a má-fé do terceiro adquirente e fazendo a comprovação, por qualquer meio admitido, de que o terceiro adquirente (a) sabia do processo que poderia levar o executado à insolvência; (b) sabia da existência do processo no qual se discutia acerca da coisa alienada; (c) tinha conhecimento da existência da constrição judicial. (FREIRE; CUNHA; 2019, p. 1.190)

Por fim, no que tange a exposição de motivos da medida provisória n. 656/2014 (BRASIL, 2014) é possível extrair dos itens 68 e 69 a urgência quanto a implementação da medida,

68. A urgência se extrai, em síntese, do disposto no parágrafo anterior, qual seja, a necessidade da adoção de uma alteração estrutural na metodologia de análise de crédito que em muito pode contribuir para mitigar a insegurança informacional hoje existente e que precisa ser tomada o quanto antes, de forma que se dissemine entre os agentes e que estes promovam os ajustes necessários a sua plena adoção. A urgência também se justifica pelo atual momento por que passa a economia brasileira, de menor entusiasmo quanto ao futuro e com carência na visualização de medidas estruturantes, que lhes antevejam melhorias que possam auxiliar na retomada do crescimento a taxas mais robustas.

Isso porque, como visto, a concentração dos atos na matrícula enquanto caminho formal a ser seguido implica em mudanças significativas acerca da análise e concessão de 
crédito aumentando consideravelmente a Segurança Jurídica dos atos, como espera e necessita a sociedade.

Pois bem, finalmente a Medida Provisória n. 656 do ano de 2014 foi convertida na LeiFederal n. 13.097 de 19 de janeiro de 2015, que inseriu no arcabouço jurídico novos ditames 
acerca da eficácia dos negócios jurídicos, assim como trouxe alterações para as Leis ns. 7.433/1985 e 11.977/2009 e para o Decreto Lei n. 754/1969. (REMÉDIO; AGUIAR, 2017)

Nos ensinamentos de Martha El Debs (2018, p. 1287) o que o artigo 54 da Lei Federal n. 13.097/2015 deixa claro é que,

[...] todo ato, seja ele judicial, administrativo ou voluntário que diga respeito ao bem ou a seu titular deve estar inscrito na matrícula do imóvel, com a finalidade de conhecimento de terceiros. Assim, com a vigência da Lei 13.097/2015, ao examinar a certidão da matrícula na Serventia Imobiliária, o comprador estará ciente se existem ou não existem, atos que possam atingir o imóvel que ele está adquirindo. O que não estiver constando na matrícula do imóvel, não atinge o imóvel.

Além disso, como explica Marcelo de Rezende Campos, citado por Martha El Debs, apesar de parecer que a norma faça referência apenas a ações judiciais e restrições de natureza administrativa, a leitura feita com atenção evidencia que "qualquer titular de direito real não registrado correrá grande risco ao não providenciar o imediato registro de seu título." (DEBS, 2018, p. 1287)

A título de adendo importa consignar que a matrícula é ato de natureza obrigatória do oficial registrador e antecedente de qualquer registro. Será emitida à vista dos atos que constam do título que foi apresentado e do registro anterior que constar do próprio cartório. Assim, quando o título anterior se encontrar registrado em cartório diverso, o título novo será entregue juntamente com a certidão atualizada, que faz prova do registro anterior, e da existência ou inexistência de eventuais ônus. (DEBS, 2018, p. 1287)

Em análise minuciosa dos itens do artigo em estudo verifica-se que o caput se refere, em regra aos direitos de natureza real e imobiliária, sobretudo os intitulados direitos limitativos da propriedade que alguns doutrinadores também denominam de ônus reais, tais como os direitos reais de uso e gozo sobre bens de terceiros, que como exemplo podem ser citados o usufruto, a servidão e a superfície; os direitos reais de garantia, que têm como exemplo a alienação fiduciária e a hipoteca; e os direitos reais decorrentes de aquisições, como os clássicos e rotineiros compromissos de compra e venda. (LOUREIRO, 2019, p. 637)

Destaca Loureiro (2019, p. 637-638):

Para ser mais exato, a ausência de registro dos respectivos títulos, nos negócios 
jurídicos entre vivos, implica na não existência de tais direitos reais em favor de terceiros, de forma que não há que se falar em ineficácia face ao registro superveniente do título de terceiro de boa-fé, mas sim em inexistência de qualquer ato, título ou direito contrário ou incompatível com aquele incorporado no título inscrito. A propriedade e os direitos reais de uso e gozo também podem ser transferidos por ato causa mortis e, neste caso, o registro do formal de partilha ou escritura de inventário e partilha (ou adjudicação) não tem efeito constitutivo, mas simplesmente declarativo. 
O inciso I trata da possibilidade de citar na matrícula a existência de ações reais ou pessoais reipersecutórias que possam atingir o imóvel, o que para Serra e Hipólito Serra (2018, p. 159) é de grande utilidade, mas tem sido ainda pouco utilizado. Acredita-se, destacam os autores, que esse fato é pela falta de conhecimento desta possibilidade pelo público em geral.

O termo "ação real" empregado no inciso I pode ser definido como "todo processo judicial que busca a tutela de um direito real". (SERRA; HIPÓLITO SERRA, 2018, p. 159).

Já as ações pessoais reipersecutórias são aquelas que, apesar de fundadas em direito pessoal, tenham a possibilidade de perseguir um bem para quitação do direito. É possível citar como exemplo a ação pauliana. (SERRA; HIPÓLITO SERRA, 2018, p. 159).

A ação pauliana, também chamada de ação revocatória, é utilizada para anular o negócio jurídico fraudulento, tendo como previsão os artigos 158 a 165 do Código Civil.

Essas constrições ou notícias, para que acessem o fólio real, devem ser averbadas na matrícula do imóvel no prazo de cinco dias, sendo que eventuais exigências quanto aos documentos apresentados para a prática do ato também deverão ser formuladas em cinco dias, já que esses pleitos ingressam na serventia através de mandado ou ofício judicial. (REMÉDIO; AGUIAR, 2017)

Por sua vez, as situações jurídicas que são trazidas nos incisos II a IV tratam-se de conjunturas subjetivas passivas que apresentam limitação ou restrição no que tange a posição jurídica do titular da propriedade ou de outro direito real imobiliário, tais como o dever genérico, obrigações, sujeições e deveres funcionais. "Essas situações passivas implicam em vinculações ou adstrições de três ordens: débitos, sujeições e ônus (aspecto passivo). " (LOUREIRO, 2019, p. 638)

Sendo assim, em caso de não averbação da penhora, não poderá ser considerada ineficaz a venda do imóvel do executado a terceiro que esteja de boa-fé em relação ao credor exequente. Não existindo inscrição de hipoteca, usufruto, entre outros ônus, o adquirente recebe o domínio livre e desembaraçado. A indisponibilidade da propriedade não deve ser mencionada pelo interessado se ele não se preocupou em providenciar a inserção da cláusula de inalienabilidade, da penhora em execução fiscal ou da hipoteca decorrente das cédulas. Inclusive, as dívidas decorrentes de créditos tributários e condominiais não devem ser cobradas 
do novo proprietário se não existir inscrição da existência das ações ou das restrições judiciais respectivas. (LOUREIRO, 2019, p. 639)

Na verdade, o artigo 54 não traz inovação no sistema de Registro Imobiliário. O que ele fez, foi fortalecer o sistema no que tange a Segurança Jurídica, a validade e eficácia dos 
atos, negócios jurídicos e direitos de cunho real ou que por qualquer motivo impactam na situação proprietária do titular registral. (LOUREIRO, 2019, p. 639)

Por fim, iniciando a conclusão do trabalho é possível afirmar que os o Princípio da Concentração proporcionou aos negócios imobiliários a Segurança Jurídica que há muito é solicitada pela população, pelos estudiosos e escritores do tema e pelos delegatários dos serviços notariais e de registro, sendo que esta novarealidade traz aos registros públicos maior "segurança jurídica, com a consequente diminuição de conflitos e litígios que iriam desaguar no abarrotado Poder Judiciário brasileiro." (REMÉDIO; AGUIAR, 2017)

\section{CONSIDERAÇÕES FINAIS}

Através da presente pesquisa observou-se que a propriedade imobiliária é de extrema relevância para a sociedade e passou por diversas mudanças desde o descobrimento do Brasil, valendo destacar como grandes marcos o sistema das sesmarias e o registro de hipotecas abordados logo no item primeiro, que sem prejuízo dos demais sistemas e normativas que os sucederam, representaram avanços no que diz respeito a publicidade de registro e o incentivo a concessão de crédito no país.

Adiante, especificamente em relação a Lei n. 6.015/73, intitulada de Lei dos Registros Públicos, pode-se concluir que foi o diploma legal divisor de águas do sistema, já que tentou concentrar em uma única lei, todas as diretrizes para o sistema registral brasileiro, representando o principal norte do Código Civil de 2002, que enfatizou a proteção dos direitos reais dos brasileiros.

Além disso, foi possível auferir que sendo a atividade registral exercida em caráter privado com delegação a um particular, fiscalizada pelo ente estatal, tem em seu núcleo o objetivo de garantir publicidade, autenticidade, segurança e eficácia dos atos e negócios jurídicos celebrados diariamente pela sociedade.

Para tanto, a atividade descrita se utiliza de diversos princípios norteadores que embora parcialmente descritos no parágrafo anterior (segurança, publicidade) com a narração da competência registral, mereceram destaque especificamente neste trabalho o Princípio da 
Concentração e o Princípio da Segurança Jurídica.

Foi possível perceber que o Princípio da Concentração tem como escopo literalmente concentrar todas as informações inerentes ao imóvel em seu cadastro oficial (matrícula), seja através de atos de registro ou averbação 
Contudo, o Princípio da Concentração, como visto, ganhou destaque e inserção explícita e formal apenas com o advento da Lei n. 13.097/2015, em seu artigo 54, parágrafo único, ao prever claramente que qualquer fato que ali não esteja inscrito não pode ser oposto perante terceiro.

Ou seja, em caso de não averbação da penhora, não inscrição da hipoteca ou do usufruto, ou mesmo a ausência de inserção da informação da indisponibilidade do bem, entre tantos outros exemplos que podem ser citados, não é possível que tais ônus sejam opostos perante o novo proprietário ou terceiro envolvido.

Dessa forma, conclui-se facilmente que o artigo 54 não inovou no arcabouço jurídico trazendo instituto inédito, mas ratificou seriamente o Princípio da Concentração, contribuindo para que ele caminhe para sua plenitude, e naturalmente aumentando de forma significativa a Segurança Jurídica do adquirente de boa-fé, comprovando a hipótese inicialmente prevista para o problema de pesquisa deste breve trabalho.

\section{REFERÊNCIAS}

AGUIAR VALLIM, João Rabello de. Direito Imobiliário Brasileiro (doutrina eprática). Revista dos Tribunais, $2^{\text {a }}$ edição, 1984.

BRASIL. Exposição de Motivos da Medida Provisória no 656/2014 - 2014. Disponível em: <http://www.planalto.gov.br/ccivil_03/_ato2011-2014/2014/Exm/ExmMPv656-14.doc>. Acesso em 11 jan. 2019.

BRASIL. Superior Tribunal de Justiça. Súmula n. 239. Disponível em: <https://ww2.stj.jus.br/docs_internet/revista/eletronica/stj-revista-sumulas2011_18_capSumula239.pdf> Acesso em: 08 jan. 2020.

BRASIL. Constituição da República Federativa do Brasil de 1988. Disponível em: $<$ http://www.planalto.gov.br/ccivil_03/constituicao/constituicao.htm> Acesso em: 07 jan.2020.

BRASIL. Lei n. 6.015 de 31 de dezembro de 1973. Lei de Registros Públicos. Disponível em: <http://www.planalto.gov.br/ccivil_03/leis/L6015compilada.htm> Acesso em 07 jan. 2020.

BRASIL. Lei n. 8.935 DE 18 DE NOVEMBRO DE 1994. Lei dos Cartórios. Disponível em: <http://www.planalto.gov.br/ccivil_03/LEIS/L8935.htm> Acesso em: 08 jan. 2020. 
BRASIL. Lei n. 10.406 de 10 de janeiro de 2002. Código Civil de 2002. Disponível em: <http://www.planalto.gov.br/ccivil_03/leis/2002/110406.htm> acesso em: 07 jan. 2020. 
BRASIL. Lei n. 13.097/2015 de 07 de outubro de 2015. Disponível em: <http://www.planalto.gov.br/ccivil_03/_Ato2015-2018/2015/Lei/L13097.htm> Acesso em: 12 jan. 2020.

CARVALHO, Afrânio de. Registro de Imóveis. 2. ed. Rio de Janeiro: Forense, 1976.

DEBS, Martha El. Legislação Notarial e de Registros Públicos: comentadas, doutrina, jurisprudência e questões de concursos. Salvador: JusPodivm, $3^{\text {a }}$ ed., 2018.

ERPEN, Décio Antônio. LAMANA PAIVA, João Pedro. O princípio da concentração dos atos registrais na matrícula imobiliária. Disponível em: $<$ https://irib.org.br/noticias/detalhes/o-princ-iacute-pio-da-concentra-ccedil-atilde-o-dosatos-registrais-na-matr-iacute-cula-imobili-aacute-ria/> Acesso em 07 jan. 2020.

FREIRE, Rodrigo da Cunha Lima; CUNHA, Maurício Ferreira. Código de Processo Civil para concursos. Salvador: Jus Podivm, 9ª ed., 2019.

JACOMINO, Sergio. Série Direito Registral e Notarial: Registro de Imóveis e eio ambiente. São Paulo: Saraiva, 2017.

LOUREIRO, Luiz Guilherme. Registros públicos: teoria e prática. 10. ed. Salvador: Editora Juspodivm, 2019.

MELO, Marcelo Augusto Santana de. Breves anotações sobre o Registro de Imóveis. Disponível em: <https://anoreg.org.br/images/arquivos/parecerrr.pdf> Acesso em 10 jan. 2020.

MINAS GERAIS. Tribunal de Justiça do Estado de Minas Gerais. PROVIMENTO No 260/CGJ/2013. Código de Normas da Corregedoria-Geral de Justiça do Estado de Minas Gerais. Disponível em: $\langle\underline{\text { http://www8.tjmg.jus.br/institucional/at/pdf/cpr02602013.pdf }>}$ Acesso em 10 jan. 2020.

PAIVA, João Pedro Lamana; ERPEN, Décio Antônio. Panorama Histórico do Registro de Imóveis no Brasil. Disponível em: 〈http://registrodeimoveis1zona.com.br/?p=270> Acesso em 13 jan. 2020.

REALE, Miguel. Lições preliminares de direito. 26. ed. São Paulo: Saraiva, 2002.

REMÉDIO, Antônio; AGUIAR, Marcos Vinicius Pacheco. A Lei 13.097/2015 e a efetivação do Princípio da Concentração no Registro de Imóveis. Disponível em:

<http://www.revista.unisal.br/lo/index.php/direitoepaz/article/view/533> Acesso em $06 \mathrm{dez}$. 2019.

RIO GRANDE DO SUL. Tribunal de Justiça do Rio Grande do Sut 2019. Agravo de Instrumento 70080673346. Relator Desembargador Cairo Roberto Rodrigues Madruga.

Revista de Direito Urbanístico, Cidade e Alteridade | e-ISSN: 2525-989X | Encontro Virtual | v. 6 | n. 2 | p. 18 - 55 | Jul/Dez. 2020. 
Disponível em: <https://www.tjrs.jus.br/novo/processos-e-servicos/processo-eletronico/portaldo-processo-eletronico/> Acesso em: 14 jan. 2020.

RIO GRANDE DO SUL. Tribunal de Justiça do Rio Grande do Sul - 2018. Apelação Cível 70077676732. Desembargador Relator Liege Puricelli Pires. Disponível em: 
<https://www.tjrs.jus.br/novo/processos-e-servicos/processo-eletronico/portal-do-processoeletronico/> Acesso em: 14 jan. 2020.

RIO GRANDE DO SUL. Tribunal de Justiça do Rio Grande do Sul - 2017. Apelação Cível 70074899220. Relator Desembargador Giovanni Conti. Disponível em: <https://www.tjrs.jus.br/novo/processos-e-servicos/processo-eletronico/portal-do-processoeletronico/> Acesso em: 14 jan. 2020.

RIO GRANDE DO SUL. Tribunal de Justiça do Rio Grande do Sul - 2019. Apelação Cível 70081853483. Relatora Desembargadora Mylene Maria Michel. Disponível em: <https://www.tjrs.jus.br/novo/processos-e-servicos/processo-eletronico/portal-do-processoeletronico/> Acesso em: 14 jan. 2020.

RIO GRANDE DO SUL. Tribunal de Justiça do Rio Grande do Sul - 2019. Apelação Cível 70081724296. Relatora Desembargadora Mylene Maria Michel. Disponível em: <https://www.tjrs.jus.br/novo/processos-e-servicos/processo-eletronico/portal-do-processoeletronico/> Acesso em: 14 jan. 2020.

SANTA CATARINA. Tribunal de Justiça de Santa Catarina-2018. Apelação Cível 001759402.2011.8.24.0033. Relatora Desembargadora Cláudia Lambert de Faria. Disponível em: https://esaj.tjsc.jus.br/cposgtj/open.do Acesso em: 14 jan. 2020.

SANTA CATARINA. Tribunal de Justiça de Santa Catarina- 2012. Apelação Cível 2008.008796-5. Relator Desembargador Luiz Fernando Boller. Disponível em: https://esaj.tjsc.jus.br/cposgtj/open.do Acesso em: 14 jan. 2020.

SANTA CATARINA. Tribunal de Justiça de Santa Catarina 2019. Apelação Cível 030296512.2015.8.24.0064. Relator Desembargador Robson Luz Varella. Disponível em: https://esaj.tjsc.jus.br/cposgtj/open.do Acesso em: 14 jan. 2020.

SANTA CATARINA. Tribunal de Justiça de Santa Catarina-2013. Agravo de Instrumento 2012.068343-0. Relator Desembargador Henry Petry Junior. Disponível em: https://esaj.tjsc.jus.br/cposgtj/open.do Acesso em: 14 jan. 2020.

SANTA CATARINA. Tribunal de Justiça de Santa Catarina - 2019. Agravo de Instrumento 0001221-98.2007.8.24.0011. Relator Desembargador Jorge Luis Costa Beber. Disponível em: <https://esaj.tjsc.jus.br/cposgtj/open.do > Acesso em: 14 jan. 2020.

SERRA, Márcio Guerra; HIPÓLITO SERRA, Monete. Registro de Imóveis I: parte geral. Christiano Cassetari (coordenação). São Paulo: Saraiva, 2016, $2^{\mathrm{a}}$ ed.

SERRA, Márcio Guerra; HIPÓLITO SERRA, Monete. Registro de Imóveis II: atos ordinatórios. Christiano Cassetari (coordenação). São Paulo: Saraiva, 2018, $3^{\mathrm{a}}$ ed. 